\title{
Conotruncal anomaly face syndrome is associated with a deletion within chromosome 22q11
}

\author{
J Burn, A Takao, D Wilson, I Cross, K Momma, R Wadey, P Scambler, J Goodship
}

Division of Human

Genetics, University of Newcastle upon Tyne, 19/20 Claremont Place, Newcastle upon

Tyne NE2 4AA, UK.

J Burn

D Wilson

I Cross

J Goodship

The Heart Institute of Japan, Tokyo Women's Medical

College, Japan.

A Takao

K Momma

Molecular Medicine

Unit, Institute of

Child Health, 30

Guilford Street,

London, UK.

R Wadey

P Scambler

Correspondence to Professor Burn.

Received 28 May 1993. Revised version accepted 7 July 1993 .
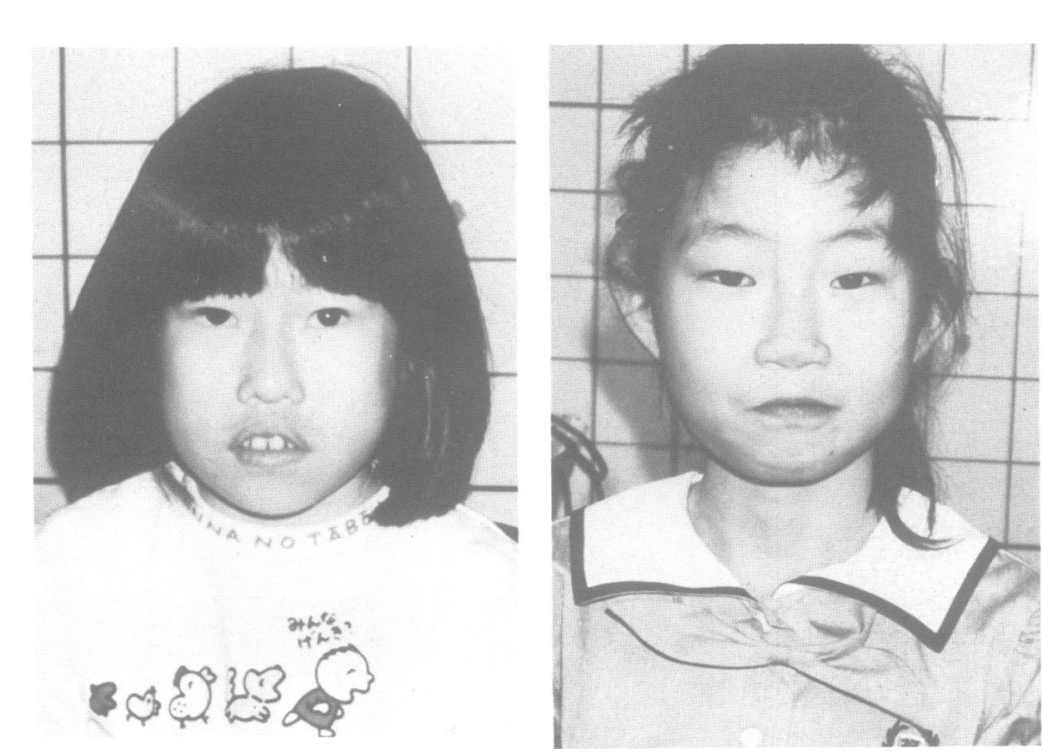

Figure 1 Facial appearance of the two older girls aged 9 and 10 years.

\begin{abstract}
The conotruncal anomaly face syndrome was described in a Japanese publication in 1976 and comprises dysmorphic facial appearance and outflow tract defects of the heart. The authors subsequently noted similarities to Shprintzen syndrome and DiGeorge syndrome. Chromosome analysis in five cases did not show a deletion at high resolution, but fluorescent in situ hybridisation using probe DO832 showed a deletion within chromosome 22q11 in all cases.

(7 Med Genet 1993;30:822-824)
\end{abstract}

Kinouchi et al in 1976 reported a recognisable phenotype, the conotruncal anomaly face (CTAF) syndrome, comprising a variety of cardiac outflow tract defects and characteristic facies with hypertelorism, lateral displacement of the inner canthi, a flat nasal bridge, narrow palpebral fissures, a nasal voice, and minor ear anomalies. In subsequent analysis ${ }^{2}$ it was suggested that this was a frequent phenotype among patients with outflow tract defects such as tetralogy of Fallot. The authors subsequently noted the heterogeneity of this syndrome and its association with thymic involution. ${ }^{3}$ They noted the overlap with the syndrome later described by Shprintzen $e t a l^{4}$ and subsequent reviews noted the likelihood that these syndromes were differing manifestations of the same phenotype. ${ }^{56}$ Following the demonstration of 22q11 deletion in almost all cases of DiGeorge syndrome ${ }^{78}$ and Shprinzten syndrome $e^{910}$ and in familial heart defects ${ }^{11}$ it was decided to investigate children with the CTAF syndrome for this chromosome abnormality. We report the investigation of five affected subjects by high resolution karyotype analysis and chromosome fluorescent in situ hybridisation (FISH).

\section{Methods}

Five patients, two males aged 3 and 24 years and three females aged 7,9 , and 10 years, with CTAF syndrome were reviewed and a peripheral venous blood sample obtained. All five had tetralogy of Fallot with pulmonary atresia and a major aorticopulmonary collateral artery, typical features of CTAF syndrome. ${ }^{12}$ The facial appearances of the two older girls are shown in fig 1 . The one adult examined (fig 2A) had mild intellectual impairment with an intelligence quotient $2 \mathrm{SD}$ below the mean. There was some uncertainty over whether this subject fulfilled the dysmorphic diagnosis, but subsequent review of a picture taken at 4 years (fig 2B) showed facial features consistent with the diagnosis.

High resolution cytogenetic analysis was attempted in each case on cell cultures established within 24 hours from the blood sample using a technique previously described. ${ }^{13} \mathrm{High}$ resolution banding was achieved if band $22 q 11.22$ could be visualised in one of the pair of chromosomes 22 (Standing Committee on Human Cytogenetic Nomenclature).

FISH was performed by a method previously described. Briefly, probe DO832 was labelled with digoxigenin by nick translation. This was hybridised to denatured chromosome preparations. The hybridised probe was then detected using fluorescein labelled antidigoxigenin antibody. The chromosomes were stained with propidium iodide and then visualised using a Nikon fluorescent microscope.

FISH analysis was performed on each patient with CTAF and also two normal subjects. Twenty metaphases from each patient and normal subject were analysed.

\section{Results}

High resolution chromosome banding was achieved in two of the five CTAF cases and both had a normal karyotype. In the remaining three cases the resolution was insufficient to identify band 22q11.22 and therefore the presence of a deletion could not be excluded. FISH analysis of the two normal subjects detected fluorescent signal on both chromosomes 22 in 

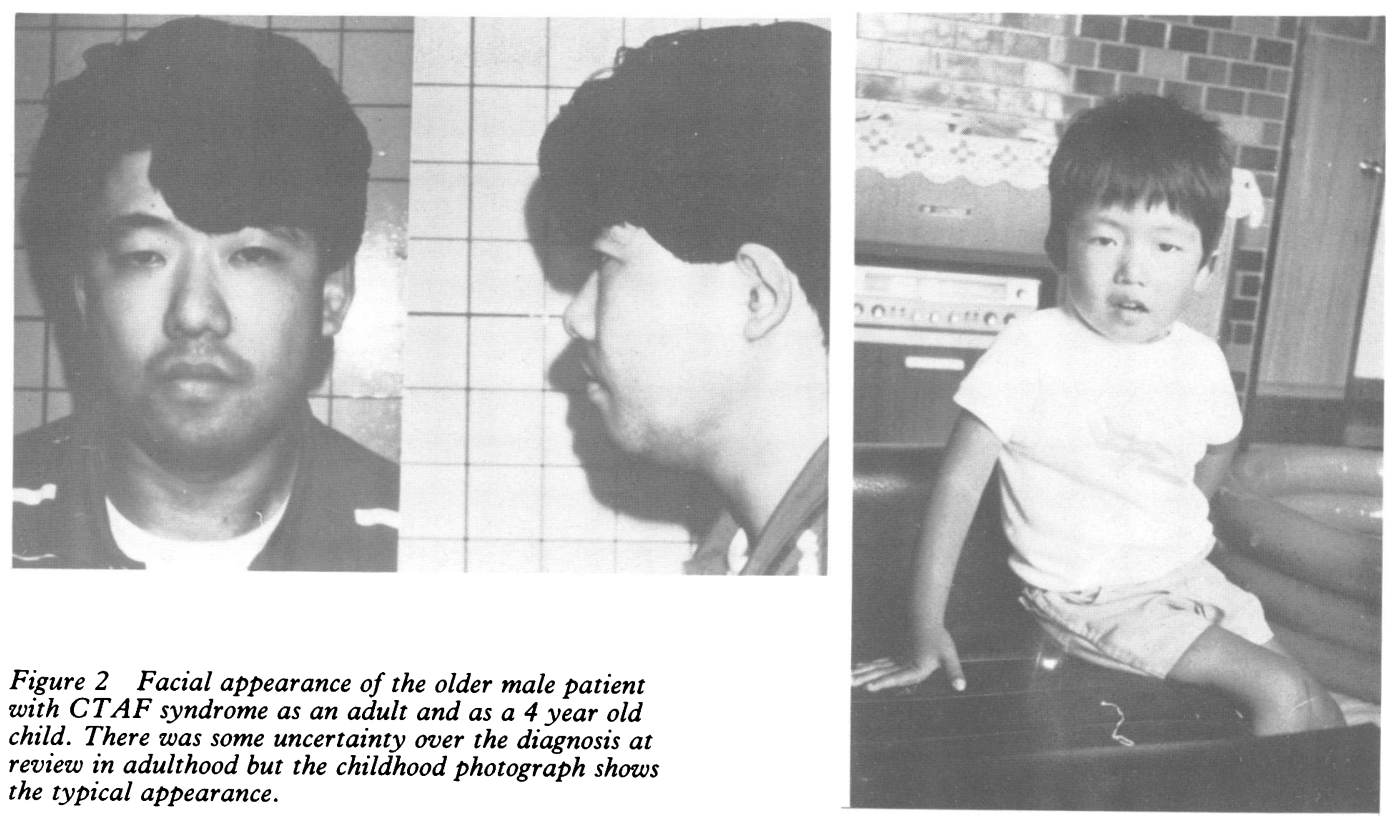

Figure 2 Facial appearance of the older male patient with $C T A F$ syndrome as an adult and as a 4 year old child. There was some uncertainty over the diagnosis at review in adulthood but the childhood photograph shows the typical appearance.

all 20 metaphases examined. Analysis of all five subjects with CTAF detected only one signal per metaphase in all the nuclei examined (fig 3).

\section{Discussion}

We have shown that CTAF syndrome is associated with a deletion within chromosome 22q11. Similar deletions have been identified in subjects with DiGeorge and Shprintzen syndromes. The precise nature of the deletions within this region of chromosome 22 have not been shown to be identical in each of these syndromes. These results support the clinical suspicion, however, of a phenotypic overlap indicating a common aetiology. The facial features summarised by Takao et al (table) correspond closely to those in DiGeorge syndrome reviewed in this issue. ${ }^{14}$

Deletions within chromosome 22q11 may be responsible for a significant proportion of cases of cardiac defects either within a syndromic pattern or in apparent isolation. This has important implications for estimating the risk of recurrence in patients with cardiac defects.

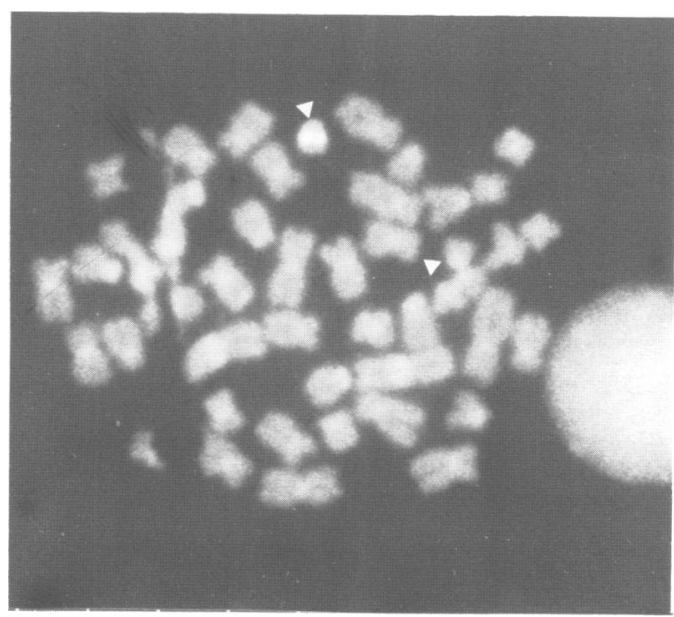

Figure 3 A metaphase spread from one of the patients with CTAF showing a single fluorescent signal after FISH with probe DO832.
The characteristics of conotruncal anomaly face syndrome of 50 cases.

$\begin{array}{lr}\text { Small mouth } & 44 / 50 \\ \text { Ocular hypertelorism } & 43 / 50 \\ \text { Mild lateral displacement of inner canthi } & 42 / 50 \\ \text { Short palpebral fissures } & 26 / 50 \\ \text { Bloated eye lids } & 41 / 50 \\ \text { Low nasal bridge } & 43 / 50 \\ \text { Strabismus } & 5 / 50 \\ \text { Ptosis of eyelid } & 2 / 50 \\ \text { Nasal voice } & 39 / 47 \\ \text { High arched palate } & 25 / 47 \\ \text { Cleft soft palate } & 1 / 47 \\ \text { Malformed auricles } & 35 / 50 \\ \text { Prominent ears } & 19 / 50 \\ \text { Incomplete scapha helix development } & 14 / 50 \\ \text { Low set ears } & 6 / 50 \\ \text { Moderate conductive deafness } & 2 / 50 \\ \text { Mild mental retardation } & 18 / 50\end{array}$

Reproduced with permission from Etiology and morphogenesis of congenital heart disease, van Praagh R, Takao A, eds. NY:
Futura, 1980 .

The belief that DiGeorge, Shprintzen, and CTAF syndromes are distinct may ultimately be seen to be the result of each group's special area of expertise in, respectively, immunology, craniofacial malformation, and cardiology. It seems increasingly likely that these eponymous syndromes will be phenotypic variations on a theme.

1 Kinouchi A, Mori K, Ando M, Takao A. Facial appearance of patients with conotruncal anomalies. Pediatr $f_{p n}$

2 Takao A, Ando M, Cho K, Kinouchi A, Murakami Y. Etiologic categorization of common congenital heart disease. In: van Praagh $\mathbf{R}$, Takao A eds. Etiology and morphogenesis of congenital heart disease. NY: Futura 1980:253-69.

3 Shimizu T, Takao A, Ando M, Hirayama A. Conotruncal anomaly face syndrome: its heterogeneity and association with thymus involution. In: Nora JJ, Takao A, eds. Congenital heart diseases: causes and processes. NY: Futura,

4 Shprintzen RJ, Goldberg RB, Lewin ML, et al. A new syndrome involving cleft palate, cardiac anomalies, typical facies, and learning disabilities: velo-cardiofacial syndrome. Cleft Palate $\mathcal{f} 1978 ; 15: 56-62$.

5 Neill CA. Congenital cardiac malformations and syndromes. In: Pierpoint ME, Moller JH, eds. Genetics of cardiovascular disease. Boston: Martinus Nijhoff, 1987:95-112.

6 Burn J. Editorial note. The face and immune system in tetralogy of Fallot. Int $\mathcal{f}$ Cardiol 1989;22:237-9.

7 Scambler PJ, Carey AH, Wyse RK, et al. Microdeletions within 22q11 associated with sporadic and familial DiGeorge syndrome. Genomics 1991;10:201-6.

8 Carey AH, Kelly D, Halford S, Molecular genetic study of the frequency of monosomy 22q11 in DiGeorge syndrome. Am ₹ Hum Genet 1992;51:964-70.

9 Scambler PJ, Kelly D, Lindsay E, et al. Velo-cardio-facial 
syndrome associated with chromosome 22 deletions encompassing the DiGeorge locus. Lancet 1992;339:1138-9.

10 Driscoll DA, Spinner NB, Budarf ML, et al. Deletions and microdeletions of $22 \mathrm{q} 11.2$ in velo-cardio-facial syndrome. Am $\mathcal{F}$ Med Genet 1992;44:261-8.

11 Wilson DI, Goodship JA, Burn J, Cross IE, Scambler PJ. Deletions within chromosome 22q11 in familial congenital heart disease. Lancet 1992;340:573-5.

12 Takao A, Terai M, Ando M, Momma K. Cardiovascular malformations in the conotruncal anomaly face syndrome In: Doyle EF, Engle MA, Gersony WM, et al, eds. Pediatric cardiology. Proceedings of the second world congress. New York: Springer-Verlag, 1985:926-28.

13 Wilson DI, Cross IE, Goodship JA, et al. A prospective cytogenetic study of 36 cases of DiGeorge syndrome. $A m$ f Hum Genet 1992;51:957-63.

14 Wilson DI, Burn J, Scambler P, Goodship J. Syndrome of the month. DiGeorge syndrome: part of CATCH 22. $f$ Med Genet 1993;30:852-6. 